\section{Screening for Aspergillus flavus Resistance in Almond}

\author{
F. Dicenta ${ }^{1}$, P. Martínez-Gómez ${ }^{2}$, and E. Martínez-Pato \\ Departamento de Mejora y Patología Vegetal, CEBAS-CSIC, P.O. Box 4195, \\ E-30080 Murcia, Spain
}

\section{T.M. Gradziel}

Department of Pomology, University of California-Davis, Davis, CA 95616

Additional index words. Prunus dulcis, aflatoxins, breeding

\begin{abstract}
Aspergillus flavus Link. is a filamentous fungus affecting almond [Prunus dulcis (Mill.) D.A. Webb] kernels in the field and during storage. This fungus can produce aflatoxins (carcinogenic and immunosuppressive mycotoxins), which prevent the marketability of almond kernels. Aspergillus flavus resistance has not been an objective in conventional almond breeding programs. Because the importance of this disease is increasing, evaluations of cultivar susceptibility are being performed. In this study, the screening for $A$. flavus resistance in $\mathbf{4 0}$ almond genotypes has been carried out in controlled inoculation conditions at $26^{\circ} \mathrm{C}$. Eighteen days after the inoculation, kernels of all the almond cultivars assayed showed susceptibility to A. flavus. Nevertheless, differences among cultivars in the percentage of kernel surface colonized by the fungus were observed. The Spanish cultivar Ramillette was the least susceptible. Susceptibility was not related to the geographic origin of the cultivar.
\end{abstract}

Aspergillus flavus Link. is a filamentous fungus affecting almond kernels. Both in the orchards and during storage it produces aflatoxins (carcinogenic and immunosuppressive mycotoxins) (Phillips et al., 1976, 1979; Schatzki and Ong, 2000, 2001), that are dangerous to animals and humans (Diener et al., 1987).

Preliminary A. flavus resistance has not been an objective in conventional almond breeding programs. However, due to the importance of this disease for the commercialization of almond kernels, studies to assess almond susceptibility to this fungus have been initiated. The aflatoxin limit allowed for almond exportation is typically $4 \mathrm{ppb}$ (Hua et al., 1998; Stoloff, 1976). The disease is more important in California cultivars with their paper shells than in European cultivars with hard well-sealed shells (Gradziel and Wang, 1994; Schade et al., 1975).

Sources of resistance to A. flavus have been described in peanuts (Arachishypogaes L.) and groundnut (Mehan, 1989; Mixon and Rogers, 1973), cotton (Gossypium hirsutem L.) (Amalraj and Meshran, 1981), and maize (Wallin, 1986). In the almond breeding program at the University of California-Davis, the studies of Aspergillus resistance in California almond cultivars revealed that, while significant differences were detected, most tested cultivars were susceptible to the fungus (Gradziel and Wang, 1994; Gradziel et al., 2000).

Received for publication 15 Feb. 2002. Accepted for publication 14 May 2002. This study was financed by project "Mejora Genética del Almendro" (AGF980211-C03-02) of the Spanish Ministry of Science and Technology.

${ }^{1}$ To whom reprint requests should be addressed. E-mail address: fdicenta@cebas.csic.es)

${ }^{2}$ Current address; Dept. of Pomology, Univ. of California-Davis, Davis CA-95616
Resistance to A. flavus has been reported to be associated with fatty acid composition and metabolism in groundnuts and maize (Zea mays L.) (Reding and Harrison, 1994; Zeringue et al., 1996). Nevertheless, in almond no correlations were detected between A. flavus aflatoxin production or mold growth and kernel oil composition (Gradziel et al., 2000).

In this study, 40 almond genotypes from different geographical origins (Medierranean area, Central Europe, California, and Australia) were evaluated for resistance to A. flavus in controlled inoculation conditions in petri dishes at $26^{\circ} \mathrm{C}$.

\section{Materials and Methods}

Almond cultivars. Forty almond cultivars were assayed (Table 2). They include diverse cultivars from Spain (24), France (5), Italy (2), Portugal (1), Tunisia (1), Ukraine (1), United States (5), and Australia (1), and 'S3056', a bitter genotype obtained in CEBAS-CSIC (Murcia, Spain).

Aspergillus flavus isolate. The A. flavus isolate 'NRRL 6412' from the "Colección EspaType Cultures) of the Universidad Politécnica de Valencia (Valencia, Spain) (Dawson et al., 1990) was used for the inoculation.

Resistance evaluation. Resistance of almond cultivars to A. flavus was evaluated following controlled inoculation conditions in petri dishes. For each cultivar both whole ñola de Cultivos Tipo" (Spanish Collection of kernels with the seedcoat and kernels cut longitudinally between the two cotyledons were assayed. For cut kernels, cotyledons were placed with the cut side facing upward. Both whole and cut kernels were inoculated by spraying $0.6 \mathrm{~mL}$ of an A. flavus spore solution $\left(2 \times 10^{6}\right.$ spores $\left./ \mathrm{mL}\right)$ to each petri dish.

For each cultivar, three petri dishes with five kernels in each were studied. To maintain high humidity, a piece of wet $(0.5 \mathrm{~mL}$ water $)$ filter paper was placed on the bottom of each dish. After inoculation, petri dishes were incubated at $26{ }^{\circ} \mathrm{C}$, in darkness. The percentages of kernel surface $(25 \%, 50 \%, 75 \%$, and $100 \%)$ colonized by the fungus and in sporulation were recorded 3 and $18 \mathrm{~d}$ after inoculation. Differences among cultivars for both traits, in whole and cut kernels, 3 and $18 \mathrm{~d}$ after inoculation were analyzed by means of the nonparametric Kruskal-Wallis test, using the SPSSX statistical package (SPSSX, 1986).

\section{Results and Discussion}

The Kruskal-Wallis test showed significant differences between cultivars for the surface colonized by the fungus and the surface in sporulation, in whole and cut kernels, 3 and $18 \mathrm{~d}$ after inoculation (Table 1).

Eighteen days after inoculation, kernels of all the assayed cultivars appeared to be susceptible to A.flavus, although some differences of susceptibility can be observed (Table 2). At this time a good correlation between the surface colonized by the fungus and the surface in sporulation was observed. This correlation was smaller at $3 \mathrm{~d}$ after inoculation. In general, the proportion of surface sporulating was smaller than the proportion of colonized surface.

A strong effect of the seedcoat on the level of infection by Aspergillus was observed. For intact kernels with seedcoats, the proportion of surface colonized by the fungus $18 \mathrm{~d}$ after inoculation averaged $8.52 \%$, compared to $82.10 \%$ for cut kernels.

Three days after inoculation of whole kernels, the proportion of kernel surface colonized did not exceed $15 \%$, being $0 \%$ in many cultivars. However, $18 \mathrm{~d}$ after the inoculation, the proportion of kernel surface colonized by the fungus increased, and cultivars Achaak, Fournat, and Glorieta showed a higher susceptibility with surface colonization exceeding $25 \%$.

For cut kernels, the proportion of colonized surface three days after inoculation often exceeded $25 \%$ in 'Cebas-1', 'Del Cid', 'Desmayo-2', 'Jordi', 'Marcona-2', 'Masbovera', 'Pajarera', 'Peraleja', 'Ramillete', 'Tuono', and 'Wawona' and it exceeded 50\% in the very susceptible cultivars Ferragnès, Ardechoise and Genco. Most of the remaining

Table 1. Kruskal-Wallis test for the percentage of surface colonized by A. flavus and in sporulation of whole and cut kernel for 40 almond cultivars, 3 and $18 \mathrm{~d}$ after inoculation at $26^{\circ} \mathrm{C}$.

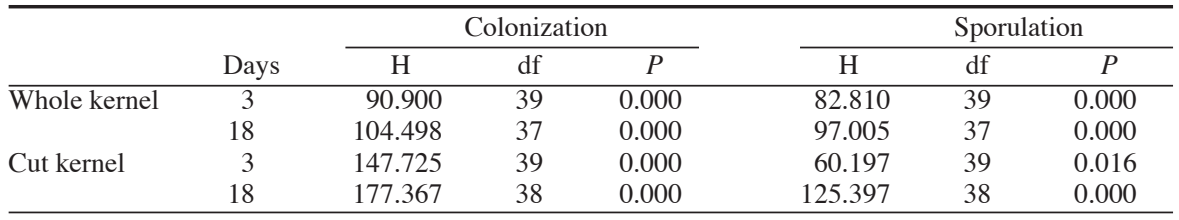


Table 2.Percentage of surface of whole and cut kernels showing colonization and sporulation by A. flavus, for 40 almond cultivars, held at $26^{\circ} \mathrm{C}$, for 3 and $18 \mathrm{~d}$ after inoculation.

\begin{tabular}{|c|c|c|c|c|c|c|c|c|c|}
\hline \multirow[b]{3}{*}{ Cultivar } & \multirow[b]{3}{*}{ Origin } & \multicolumn{4}{|c|}{ Whole kernel } & \multicolumn{4}{|c|}{ Cut kernel } \\
\hline & & \multicolumn{2}{|c|}{$3 d$} & \multicolumn{2}{|c|}{$18 \mathrm{~d}$} & \multicolumn{2}{|c|}{$3 \mathrm{~d}$} & \multicolumn{2}{|c|}{$18 \mathrm{~d}$} \\
\hline & & Colonization & Sporulation & Colonization & Sporulation & Colonization & Sporulation & Colonization & Sporulation \\
\hline Achaak & Tunisia & 0.00 & 0.00 & 25.00 & 25.00 & 35.00 & 0.00 & 88.46 & 84.61 \\
\hline Ardechoise & France & 0.00 & 0.00 & 3.57 & 3.57 & 68.33 & 0.00 & 100.0 & 100.00 \\
\hline Atocha & Spain & 0.00 & 0.00 & 2.50 & 2.50 & 40.00 & 0.00 & 100.0 & 81.67 \\
\hline Bonita & Portugal & 1.66 & 0.00 & 3.57 & 1.78 & 41.67 & 0.00 & 95.00 & 88.33 \\
\hline Carretas & Spain & 3.84 & 0.00 & 14.28 & 14.28 & 25.00 & 0.00 & 90.00 & 65.00 \\
\hline Cebas 1 & Spain & 0.00 & 0.00 & 16.66 & 6.66 & 21.67 & 0.00 & 88.64 & 65.91 \\
\hline Chellastone & Australia & 3.33 & 0.00 & 9.09 & 9.09 & 26.67 & 0.00 & 93.33 & 81.67 \\
\hline Colorada & Spain & 0.00 & 0.00 & 0.00 & 0.00 & 25.00 & 0.00 & 62.50 & 57.50 \\
\hline Del Cid & Spain & 0.00 & 0.00 & 5.00 & 3.33 & 15.00 & 0.00 & 90.00 & 78.33 \\
\hline Desmayo L-1 & Spain & 0.00 & 0.00 & 3.57 & 1.78 & 28.33 & 0.00 & 80.36 & 67.86 \\
\hline Desmayo L-2 & Spain & 1.66 & 0.00 & 3.84 & 3.84 & 23.33 & 0.00 & 80.36 & 78.57 \\
\hline Ferraduel & France & 0.00 & 0.00 & 0.00 & 0.00 & 48.33 & 0.00 & 83.33 & 61.67 \\
\hline Ferragnès & France & 8.33 & 5.00 & 18.18 & 13.63 & 66.67 & 0.00 & 93.33 & 91.67 \\
\hline Fournat & France & 13.33 & 5.00 & 75.00 & 50.00 & 48.33 & 3.33 & 96.57 & 93.75 \\
\hline Garrigues & Spain & 0.00 & 0.00 & 0.00 & 0.00 & 41.67 & 0.00 & 93.33 & 70.00 \\
\hline Genco & Italy & 0.00 & 0.00 & --- & --- & 66.67 & 0.00 & 100.00 & 86.67 \\
\hline Glorieta & Spain & 0.00 & 0.00 & 25.00 & 12.50 & 40.00 & 0.00 & 84.37 & 78.12 \\
\hline Guara & Spain & 0.00 & 0.00 & 7.50 & 5.00 & 38.33 & 0.00 & 91.67 & 91.67 \\
\hline I.X.L. & USA & 1.66 & 0.00 & 4.54 & 2.27 & 33.33 & 0.00 & 88.33 & 85.00 \\
\hline Jordi & Spain & 0.00 & 0.00 & 0.00 & 0.00 & 18.33 & 0.00 & 60.00 & 57.50 \\
\hline Lauranne & France & 6.66 & 0.00 & 3.57 & 3.57 & 30.00 & 0.00 & 58.33 & 58.33 \\
\hline La Mona & Spain & 3.33 & 0.00 & 5.76 & 3.84 & 31.67 & 0.00 & 86.54 & 86.54 \\
\hline Malagueña & Spain & 3.33 & 0.00 & 13.46 & 13.46 & 28.33 & 3.33 & 91.67 & 91.67 \\
\hline Marcona-1 & Spain & 0.00 & 0.00 & 1.66 & 1.66 & 25.00 & 0.00 & 91.67 & 81.67 \\
\hline Marcona-2 & Spain & 0.00 & 0.00 & 0.00 & 0.00 & 16.67 & 0.00 & 72.50 & 72.50 \\
\hline Marcona-3 & Spain & 0.00 & 0.00 & 3.33 & 1.66 & 25.00 & 0.00 & 100.0 & 81.67 \\
\hline Masbovera & Spain & 6.66 & 0.00 & 10.00 & 5.00 & 20.00 & 0.00 & 70.00 & 67.50 \\
\hline Mono & USA & 1.66 & 0.00 & 5.00 & 5.00 & 40.00 & 0.00 & 77.50 & 77.50 \\
\hline Pajarera & Spain & 3.33 & 0.00 & 12.50 & 7.50 & 23.33 & 0.00 & 94.64 & 89.29 \\
\hline Peraleja & Spain & 1.66 & 1.66 & 14.58 & 14.58 & 21.67 & 0.00 & 65.00 & 65.00 \\
\hline Planeta-1 & Spain & 0.00 & 0.00 & 11.11 & 8.33 & 31.67 & 0.00 & 83.93 & 76.78 \\
\hline Planeta-2 & Spain & 0.00 & 0.00 & 4.16 & 4.10 & 30.00 & 0.00 & 95.00 & 95.00 \\
\hline Primorskii & Ukraine & 5.00 & 0.00 & --- & --- & 45.00 & 3.33 & --- & --- \\
\hline Ramillete & Spain & 0.00 & 0.00 & 0.00 & 0.00 & 21.67 & 0.00 & 48.21 & 42.86 \\
\hline Rumbeta & Spain & 0.00 & 0.00 & 3.12 & 3.12 & 33.33 & 0.00 & 85.00 & 80.00 \\
\hline S3056 & Spain & 0.00 & 0.00 & 0.00 & 0.00 & 26.67 & 0.00 & 56.67 & 56.67 \\
\hline Tioga & USA & 0.00 & 0.00 & 0.00 & 0.00 & 36.67 & 6.67 & 52.08 & 50.00 \\
\hline Titan & USA & 0.00 & 0.00 & 12.50 & 12.50 & 41.67 & 0.00 & 91.67 & 75.00 \\
\hline Tuono & Italy & 0.00 & 0.00 & 4.16 & 0.00 & 20.00 & 0.00 & 62.50 & 59.37 \\
\hline Wawona & USA & 8.33 & 0.00 & 9.09 & 9.0. & 21.67 & 0.00 & 59.61 & 59.61 \\
\hline
\end{tabular}

cultivars ranged between these values (25\% and $50 \%$ ). Eighteen days after the inoculation of cut kernels, the proportion of kernel surface colonized by the fungus increased greatly. Only the Spanish cultivar Ramillete did not reach $50 \%$ surface colonization. For cultivars, such as 'Colorada', 'Jordi', 'Lauranne', 'Marcona2', 'Masbovera', 'Peraleja', 'S3056', 'Tioga', 'Tuono', and 'Wawona', the percentage of surface colonized ranged between $50 \%$ and $75 \%$. No important difference in level of resistance was observed between the bitter selection 'S3056' and sweet cultivars. The remaining cultivars exceeded $75 \%$ of colonized surface at $18 \mathrm{~d}$ after inoculation, with some cultivars ('Primorskii', 'Marcona-3', 'Genco', 'Atocha', and 'Ardechoise') completely covered by the fungus.

Our results agree with those of Gradziel and Wang (1994) who studied the susceptibility to A. flavus in a selection of 21 California cultivars. Among these was 'Mono', which performed similarly in our test. They observed a high susceptibility for most of cultivars, and only 'Ruby' and 'Ne Plus Ultra' were less susceptible. Nevertheless, final colonization in whole kernels was more extensive in our assay, possibly due to environmental conditions of the trial or to the use of different isolates.

The low level of susceptibility found in the cultivars Colorada, Jordi, Marcona-2, S3056, Tioga, and Ramillete could still be useful due to the low level of Aspergillus infection commonly found in the field and the limited period of time in which the kernel can be infected (Schade et al., 1975; Schatzki and Ong, 2000, 2001). In addition, these cutlivars show a well-sealed shell that drastically reduces the possibilities of infection by the fungus in field conditions. Furthermore, the usual dry storage conditions are not adequate for the fungus multiplication.

The lack of correlation between A. flavus susceptibility and almond kernel oil composition described by Gradziel et al. (2000) may explain the failure to find resistance sources in almond. In other crops, like groundnuts and maize, an association between fatty acid composition, metabolism, and A. flavus resistance has been described (Reding and Harrison, 1994; Zeringue et al., 1996), and sources of resistance reported (Mehan, 1989; Mixon and Rogers, 1973; Reding and Harrison, 1994; Wallin, 1986; Zeringue et al., 1996).
Other sources or types of resistance to $A$. flavus might be identified in related Prunus species. For example, Gradziel et al. (2001) has recently described several almond lines resulting from the introgression of peach [Prunus persica (L.) Batsch] genes in which aflatoxin production following controlled inoculations was reduced as much as $90 \%$ relative to susceptible almond cultivars.

In conclusion, in spite of the large variability observed among cultivars, all showed susceptibility to A. flavus. The geographical origin of the cultivars was not related to their level of susceptibility. The Spanish cultivar 'Ramillete' was the least susceptible, with an additional 10 cultivars, 'Colorada', 'Jordi', 'Marcona-2', 'Masbovera', 'Peraleja', and 'S3056' (Spain); 'Lauranne' (France); 'Tioga' and 'Wawona' (United States); and 'Tuono' (Italy), showing lesser levels of susceptibility than the rest.

\section{Literature Cited}

Amalraj, S.F.A., and M.K. Meshram. 1981. Role of certain morphological characters in relation to boll rot resistance in Gossypium hirsutem L. Turrialba 31:33-35.

Dawson, C., C. Belloch, M.D. García-López, and F. 


\section{Breeding, Cultivars, Rootstocks, \& Germplasm Resources}

Uruburu. 1990. Colección española de cultivos tipo. Catálogo de cepas (in Spanish). Ed. Univ. Polit. de Valencia. Valencia, Spain.

Diener, U.L., R.J. Cole, T.H. Sanders, G.A. Payne, L.S. Lee, and M.A. Klich. 1987. Epidemiology of aflatoxin formation by Aspergillus flavus. Ann. Rev. Phytopathol. 25:249-270.

Gradziel, T.M. and D. Wang. 1994. Susceptibility of Californian almond cultivars to aflatoxigenic Aspergillus flavus. HortScience 29:33-35.

Gradziel, T.M., N. Mahoney, and A. Abdallah. 2000. Aflatoxin production among almond genotypes is not related to either kernel oil composition or Aspergillus flavus growth rate. HortScience 34:937-939.

Gradziel, T.M., P. Martínez Gómez, F. Dicenta, and D.E. Kester. 2001. The utilization of related Prunus species for almond variety improvement. J. Amer. Pom. Soc. 55:100-108.

Hua, S.S.T., J.L. Baker, and O.K. Grosjean. 1998. Improvement of the quality and value of pistachios and almonds through preharvest biocontrol of Aspergillus flavus. Acta Hort. 470:576-581.
Mehan, V.K. 1989. Screening for resistance to seed invasion by Aspergillus flavus and to aflatoxin production. In: D. McDonald and V.K. Mehan (eds.). Proc. Intl. Workshop on Aflatoxin Contamination of Groundnut. Intl. Crop. Res. Inst., Patancheru, India. 323-334.

Mixon, A.C. and K.M. Rogers. 1973. Peanut accessions resistant to seed infection by Aspergillus flavus. Agron. J. 65:560-562.

Phillips, D.J., M. Uota, D. Monticelli, and C. Curtis. 1976. Colonisation of almond by Aspergillus flavus. J. Amer. Soc. Hort. Sci. 100:19-23.

Phillips D.J., B. Mackey, W.R. Ellis, and T.N. Hansen. 1979. Occurrence and interaction of Aspergillusflavus with almond. Phytopathology 69:829-831.

Reding C.L.C. and M.A. Harrison. 1994. Possible relationship of succite dehydrogenase and fatty acid synthetase activities to Aspergillus parasiticus (NRRL 5139) growth and aflatoxin production. Mycopathologia 127:175-181.

SPSSX. 1986. SPSSX user's gsuide. McGraw-Hill, Chicago.
Schade, J.E., R. McGreevey, A.D. King, B. Mackey, G. Fuller. 1975. Incidence of aflatoxin in California almond cultivars. Appl. Microbiol. 29:48-53.

Schatzki, T.F. and Ong, M.S. 2000. Distribution of aflatoxin in almonds. 2. Distribution in almonds with heavy insect damage. J. Agr. Food Chem. 48:489-492.

Schatzki, T.F. and M.S. Ong. 2001. Dependence of aflatoxin in almonds on the type and amount of insect damage. J. Agr. Food Chem. 49: 4513-4519.

Stoloff, L. 1976. Incidence, distribution, and disposition of products containing aflatoxin. Proc. Amer. Phytopathol. Soc. 3:156-172.

Wallin, J.R. 1986. Production of aflatoxin in wounded and whole maize kernels by Aspergillus flavus. Plant Dis. 70:429-430.

Zeringue, H.J., R.L. Brown, J.N. Neucere, and T.E. Cleveland. 1996. Relationships between C6-C12 alkanal and alkenal volatile contents and resistance of maize genotypes to Aspergillus flavus and aflatoxin production. J. Agr. Food Chem. 44:403-407. 